paedics. Professor Kessel has produced a book which pictorially shows defects and deformities of all common conditions and also many rare abnormalities of the musculoskeletal system. He has also outlined many physical signs pictorially. There are fascinating sections on general disorders of the skeleton in which external body appearance is related to the equivalent $X$-rays, and in some cases to the histological microscopic appearance. The quality of photographs and Xrays is excellent and the accompanying text is brief but pertinent.

It is difficult to know to whom this book has been primarily directed, but it is an important volume for the orthopaedic department shelf as a ready handbook of pathological appearance. It will also be important for the pre-final Fellowship candidate to run rapidly through the abnormal anatomy of orthopaedic prob'ems and will also remind him pictorially of methods to elicit physical signs relevant to the musculoskeletal system.

This is a fascinating, beautifully illustrated book which I was delighted to read.

\section{Medicines. A Guide for Everybody}

By Peter Parish. 3rd edn. Pp. 462. Penguin Books, London, 1980. $£ 2.25$.

This book has established itself as a reference book on medicines for the general public and has reached its third edition within 5 years of publication or the first. The first part of the book is devoted to a general discussion on drug action within the body; the second to different areas of drug treatment, while in the third and last there is a selected pharmacopoeia of drugs listed alphabetically with limited information on their indication, adverse effects and dose. It is difficult to know what value is served by such dose statements, and many physicians would feel that they could be positively misleading, but presumably the book's success indicates that the public at large want this information. It might be expected that a 1980 publication would contain reference to nicotine formulations such as chewing gum. Why is ketotifen said to 'enhance the effects of sedatives, hypnotics, alcohol...' without simply saying that it commonly causes sedation? This book has little of direct value for workers in the health fields but may, perhaps, be recommended to patients who have an intelligent and enquiring interest in their drug treatment.

\section{Obstetric Anaesthesia and Analgesia}

By Donald D. Moir. 2nd edn. Pp. ix +326 , illustrated. Baillière Tindall, London, 1980. £12.50.

This book is authoritative, comprehensive, well-written and easy to read and reflects great credit on the author, who is an extremely experienced, dedicated and enthusiastic anaesthetist. In this, the second edition, there has been extensive revision of the text and updating of the extensive references which are included at the end of each chapter. After sections on the history of obstetric anaesthesia, the physiology of pregnancy and labour and the pharmacology of drugs used in labour come chapters on pain relief and the various techniques of general and regional anaesthesia together with chapters on obstetric, anaesthetic and medical complications and on the resuscitation of the newborn.

Throughout, the reader will be impressed by the depth and extent of the obstetric coverage which makes the book of especial interest to the obstetrician. Nor should there be dissent from the opinion of the author that, ideally, there should be continuous cover in the labour wards by experienced obstetric anaesthetists whose duties lie solely there.

It is impossible to over-emphasize the changes which have ocurred over the last 15 years, with the widespread adoption of the active management of labour and the institution of epidural services and almost impossible to visualize a return of a situation when these were not employed. Anyone unaware of the debt owed by the obstetric service to anaesthetists would do well to read this book. Although primarily directed towards anaesthetists training in this field, the book should be recommended reading for all obstetric staff, paediatricians and labour-ward personnel and must be avilable in all hospital libraries.

Operating Theatre Technique. A Textbook for Nurses, Technicians, Operating Department Assistants, Medical Students, House Surgeons and others associated with the Operating Theatre

By R. J. Brigden. 4th edn. Pp. xii +811 , illustrated. Churchill Livingstone, Edinburgh, 1980. £35.00.

Mr Brigden's textbook on Operating Theatre Technique first appeared in 1962 and rapidly became established as the standard textbook for nursing staff and operating room technicians. This new edition has been considerably extended and has been brought completely up to date. Microsurgical techniques are now being used extensively, particularly in ENT, eye, neuro- and vascular surgery; the new edition covers the use of operating microscopes and there is detailed information on procedures requiring microsurgical techniques. The other revolution well covered in the new edition is fibreoptics, and their application to urology, bronchoscopy and gastroscopy are well detailed. A welcomed addition is the use of colour and this is particularly useful in the very clear illustrations of endoscopic appearances. Many new operations, including renal transplantation, and now included and copiously illustrated.

The author is to be congratulated on bringing his textbook completely up to date. It will continue to play a valuable part in the training of one of the most important groups within the hospital - the theatre staff.

\section{Pathways in Neurological Diagnosis}

By John I. Balla. Pp. ix +124 , illustrated. Edward Arnold, London, 1980. $£ 10.00$.

The preface to this book indicates that it is directed primarily at medical students. It purports to be an illustration of how knowledge of the basic sciences and of the processes of logical thought can be applied to neurological diagnosis. In the first 3 chapters, what is termed 'the basic philosophy of neurological diagnosis within the framework of the scientific methodology of the hypothetico-deductive system' is outlined. One is relieved to learn that, in practice, this means eliciting the relevant history and physical signs and relating them to likely diagnoses. This section is followed by a brief summary ( 3 pages) of neuro-anatomy and a description of the main clinical features caused by disturbance of the various physiological systems. Subsequently there is a series of chapters on the analysis and investigation of common symptoms each followed by a flow diagram illustrating the 'diagnostic pathway'.

The student needs to learn how to extract information from a patient and how to use this to formulate a diagnosis and sound plan of management. Factual knowledge about neurological diseases is intrinsic to this process. This book is unlikely to help in these tasks. What many would call 'common-sense' in asking questions and eliciting signs has been concealed in jargon terminology (hypothetico-deductive system, the minimax principle, incongruous information) which confuses the issue. In this respect the clinical illustrations are facile in the unreal perfection of the histories and are certainly no substitute for clinical experience.

The flow diagrams attempt to constrain clinical situations to an artificial series of binary steps. In some instances this leads to potentially unsound practices. Thus the syphilis serology appears an unnecessary investigation in 'acute brain 
failure' and a patient with a cerebral abscess is likely to have a lumbar puncture but no brain scan. In the analysis of monocular blindness most paths indicate a vascular or demyelinating aetiology whilst optic nerve compression receives little emphasis.

The author is dissatisfied with traditional ways of teaching medicine. On the evidence of this book, however, he has not formulated an alternative approach which can be recommended to medical students.

\section{Principles of Clinical Psychiatry}

By Arnold M. Ludwig. Pp. ix +438 , illustrated. Baillière Tindall, London. Collier Macmillan, London. Free Press, New York, 1980. £15.00.

Professor Ludwig has produced a very idiosyncratic textbook of psychiatry. It is unashamedly medical in orientation. The book begins with an exposition of the logical basis of diagnosis in medicine and psychiatry. It continues with descriptions and definitions of the various signs and symptoms which need to be elucidated to reach a diagnosis. There are scattered treasures within these sections but it is doubtful if much of it would make sense to anyone who did not already possess more than a rudimentary knowledge of the subject. It is also true that some of the definitions of phenomena, such as obsessions, are tortuous and a little unorthodox.

The sections dealing with syndromes are logical and understandable but suffer major defects. They are insufficiently detailed for trainee psychiatrists but too detailed for nonpsychiatrists. The text is also difficult to read because Professor Ludwig is addicted to lists and tables which break the flow of the text. Chapter 15 on drug habit disorders contains 19 such lists. 2 of which each fill 3 pages.

In summary, this is not a book one could recommend for undergraduates or for postgraduates needing to brush up their psychiatry. It is not detailed enough to serve as a basic text for trainee psychiatrists. It could only serve as an interesting alternative view of psychiatry for a trainee trying to broaden his horizons in the run-up to the M.R.C.Psych.

\section{Standard Orthopaedic Operations}

By J. Crawford Adams. 2nd edn. Pp. 463, illustrated. Churchill Livingstone, Edinburgh, London and New York, 1980. $£ 18.00$.

This second edition of Standard Orthopaedic Operations upgrades and updates a book which has become an essential for all orthopaedic registrars.

The volume contains details of all commonly performed procedures and general orthopaedic techniques and exposures are well written and beautifully illustrated. Individual operations are economically but well described and there is enough detail present fully to understand operative procedures. Recently introduced techniques including the Swiss AO internal fixation method and hip and knee replacement prostheses are included. Arthroscopy is unfortunately not included in the discussion on knee operations.

The great value of this book is that the orthopaedic surgeon in training has one volume from which he can obtain a very full outline of operative procedures. The descriptions are clear and concise. The book is well illustrated and interesting - this second edition is strongly recommended.

\section{Talking with Patients. A Teaching Approach}

Observations of a Nuffield Working Party on Communica $\Omega$ tions with Patients. Pp. 55, Illustrated. Nuffield Provincia Hospitals Trust, 1980. $£ 0.50$.

The Nuffield Trust, concerned with the practical consequencess of failures of communication between doctors and patients set up a working party to consider the skills doctors need to communicate effectively and how these can be taught. Fail ures of communication occur in the 2 parts of the consulta $\frac{\infty}{-}$ tion: in the interview (when the history is taken and a diagno sis reached) and in the 'exposition' (the explanation and in struction part of the consultation). The failures are mucks more frequent, apparently, in this latter part. The documen- $\overrightarrow{0}$ ted evidence for communication problems, and ways in which they can be prevented, is based on a considerable body of recent research which is given in a most valuable annota ted bibliography compiled by Professor Charles Fletcher.

The working party is impressed by the evidence that audios visual aids can be of value in teaching communication skills 3 .

This booklet is aimed at medical tutors, and should ber read by them. There must, however, be few clinicians who could not improve their own clinical consultation techniques with the aid of this useful publication and a few moments. sober reflection.

\section{The True History of the Elephant Man}

By Michael Howell and Peter Ford. Pp. 223, illustrated.. Penguin Books, Harmondsworth, Middlesex, 1980. $£ 1.25$ Joseph Carey Merrick (1862-1890) was the Leicester-born? son of a warehouseman who was married to a crippled sern vant girl. She was also a Baptist Sunday school teacher. The name Joseph was that of his father and Carey from a leadfing Baptist preacher and missionary William Carey (1761-18 Although apparently normal at birth the infant son begantigrow grotesquely deformed from the age of 2 years onwars Swellings appeared on the lips and right cheek followed.byo bony lumps on the forehead. A mass of flesh protruded from beneath the upper lip into a grotesque snout resembling an elephant's trunk. Joseph suffered from multiple neurofibro@ matosis or von Recklinghausen's disease, named after th German Professor of Pathology (1833-1910) at the new Uni versity of Strasbourg, who described his first case in $1880 \overrightarrow{\vec{\sigma}}$ Joseph became the subject of several books, a Broadway hit a film, and he has achieved immortality as a result of the contemporary clinical and research interests of Sir Frederick Treves (1853-1923), Dorchester-born surgeon to The London. Hospital.

Eventually Joseph Merrick and Frederick Treves stoodB facing each other in the Anatomy Department of The Lon: don Hospital. Here was a surgeon accustomed to physica 3 distortion facing a fairground freak. Joseph's proportions. were grotesque, for he was scarcely $5^{\prime} 2^{\prime \prime}$ in height, with measurement of $36^{\prime \prime}$ for the head's circumference and $12^{\prime} \overline{3}$ for the right wrist and $5^{\prime \prime}$ for a swollen finger of the right hand $O$ He was presented by Treves to the Pathological Society oP London in 1884 and again in 1885 .

This paperback is a comprehensive account by a doctor and a journalist of the complex interrelationships between Joseph and Treves, beautifully written and leaving each reader tor determine where his sympathies lie. Perhaps a little bit with each of them. This is an absorbing account enriched by 30 appendices, a comprehensive bibliography and an exhause tive index. This is surely the last word and the true version of the history of the unfortunate elephant man, a fantastic account that will grip you, your wife and family from cover to cover. It is an extraordinary and moving story of a tragię Victorian and of his sad survival in a brutal world. 